\title{
0888. Administration of tetrahydrobiopterin (BH4) protects renal microcirculation after ischemia and reperfusion
}

\author{
L Rahmania*, F Su, D Orbegozo Cortés, EH Post, C Santacruz, FS Taccone, J-L Vincent, D De Backer \\ From ESICM LIVES 2014 \\ Barcelona, Spain. 27 September - 1 October 2014
}

\section{Introduction}

Abdominal aortic aneurysm surgery with supra-renal clamping is associated with potential development of renal insufficiency. Ischemia and reperfusion (I-R) produced during the procedure induces endothelial dysfunction with a decrease in tetrahydrobiopterin (BH4), a cofactor used in nitric oxide synthesis.

\section{Objectives}

To assess whether $\mathrm{BH} 4$ administration could prevent the injury to the renal microcirculation caused by suprarenal aortic clamping with I-R.

\section{Methods}

Nineteen adult sheep were anesthetized, mechanically ventilated and invasively monitored. Renal blood-flow was measured continuously through a left lumbotomy using a peri-vascular flow probe (Transonic, USA) and an aortic clamp was positioned above the renal arteries. After surgical preparation and stabilization, animals were randomized into 3 groups (SHAM=5, I-R=7, I- + +BH4=7). SHAM animals underwent surgical preparation but no aortic clamping was performed. The I- $\mathrm{R}$ groups were exposed to 1 hour of aortic ischemia. The I- $\mathrm{R}+\mathrm{BH} 4$ group received $20 \mathrm{mg} / \mathrm{kg}$ of BH4 before aortic clamping. Animals were followed for a maximum of 6 hours after reperfusion. Renal microcirculation was evaluated at baseline, and 1, 4 and 6 hours after reperfusion using Sidestream Dark Field video-microscopy (Microvision Medical, Netherlands). We calculated perfused small vessel density (PVD), proportion of perfused small vessels (PPV) and heterogeneity of PPV (PPV-HI). Data were analyzed using the generalized

Table 1 Microcirculatory parameters in the 3 groups

\begin{tabular}{|c|c|c|c|c|c|c|}
\hline & Group & Baseline & $1 \mathrm{~h}$ & $4 \mathrm{~h}$ & $6 h$ & P Group*Time \\
\hline \multirow[t]{3}{*}{ PVD (vessels/mm) } & SHAM & $2.6(2.5-2.7)$ & $2.7(2.3-2.9)$ & $2.4(2.2-2.7)$ & $2.3(2.3-2.5) c$ & $P<0.05$ \\
\hline & I-R & $3.2(2.9-3.7)$ & $2.0(1.5-2.8) \mathrm{C}$ & $2.1(1.7-2.7) \mathrm{c}$ & $1.6(1.3-2.3) a, c$ & \\
\hline & $\mathrm{I}-\mathrm{R}+\mathrm{BH} 4$ & $3.2(2.7-3.4)$ & $3.0(2.6-3.3) b$ & $2.5(2.0-3.1) b, c$ & $3.1(2.4-3.8) b$ & \\
\hline \multirow[t]{3}{*}{ PPV (\%) } & SHAM & $93.7(93.3-94.7)$ & $87.6(84.2-90.6) \mathrm{C}$ & $83.0(80.3-90.2) \mathrm{c}$ & $85.5(82.0-90.4) \mathrm{C}$ & $P=0.269$ \\
\hline & I-R & $97.3(96.0-97.9)$ & $80.1(73.5-90.2) c$ & $82.7(68.5-88.7) \mathrm{c}$ & $79.8(74.9-84.6) \mathrm{c}$ & \\
\hline & $\mathrm{I}-\mathrm{R}+\mathrm{BH} 4$ & $97.8(96.8-98.3)$ & $92.3(89.8-93.8)$ b, c & $85.9(80.9-91.5) \mathrm{c}$ & $89.3(86.0-99.4) \mathrm{c}$ & \\
\hline \multirow[t]{3}{*}{ PPV-HI (\%) } & SHAM & $11.9(8.9-13.2)$ & $18.4(16.5-22.8) \mathrm{C}$ & $14.2(11.0-15.1)$ & $14.4(11.3-39.0)$ & $P<0.05$ \\
\hline & I-R & $9.6(5.5-11.0)$ & $43.0(22.2-84.0) a, c$ & $41.8(28.2-97.7)$ a, c & $47.3(11.1-76.3) \mathrm{c}$ & \\
\hline & $\mathrm{I}-\mathrm{R}+\mathrm{BH} 4$ & $9.3(7.3-12.5)$ & $24.7(17.1-32.8) \mathrm{C}$ & $42.8(29.1-56.2) \mathrm{c}$ & $25.4(2.9-40.5) \mathrm{c}$ & \\
\hline
\end{tabular}

[values are presented as median with P25-75]

a: significant difference between groups I-R and SHAM

b: significant difference between groups $\mathrm{I}-\mathrm{R}$ and $\mathrm{BH} 4+\mathrm{I}-\mathrm{R}$

c: significant difference with the baseline. 
estimating equation (GEE) and p-values less than $5 \%$ were considered statistically significant. Results are presented as median [IQRs].

\section{Results}

The systemic hemodynamics variables were preserved in all 3 groups. BH4 was associated with improved renal function, as evaluated by creatinine after 6 hours of reperfusion in the I-R+BH4 group (14 mg/L [13-17]) compared to the I-R group (16 mg/L [16-22]) $(\mathrm{P}=0.072)$.

\section{Conclusions}

In a sheep model of renal I-R, BH4 pre-treatment can prevent microvascular injury and dysfunction. Clinical trials are warranted to evaluate the administration of BH4 to prevent I-R-induced kidney injury.

Published: 26 September 2014

doi:10.1186/2197-425X-2-S1-017

Cite this article as: Rahmania et al:: 0888. Administration of

tetrahydrobiopterin ( $\mathrm{BH} 4)$ protects renal microcirculation after ischemia

and reperfusion. Intensive Care Medicine Experimental 2014 2(Suppl 1):017.

\section{Submit your manuscript to a SpringerOpen ${ }^{\circ}$ journal and benefit from:}

- Convenient online submission

- Rigorous peer review

- Immediate publication on acceptance

- Open access: articles freely available online

- High visibility within the field

- Retaining the copyright to your article

Submit your next manuscript at $\gg$ springeropen.com 